\title{
ASSOCIATION BETWEEN AGE AT MENARCHE AND EARLY-LIFE NUTRITIONAL STATUS IN RURAL BANGLADESH
}

\author{
ALINDA M. BOSCH*, FRANS J. WILLEKENS*, ABDULLAH H. BAQUI†, \\ JEROEN K. S. VAN GINNEKEN* AND INGE HUTTER
}

\begin{abstract}
* Netherlands Interdisciplinary Demographic Institute, the Netherlands, †Department of International Health, Johns Hopkins Bloomberg School of Public Health, Baltimore, USA \& Centre for Health and Population Research, Dhaka, Bangladesh and $\$$ Population Research Centre, University of Groningen, Groningen, the Netherlands
\end{abstract}

\begin{abstract}
Summary. Age at menarche is associated with anthropometry in adolescence. Recently, there has been growing support for the hypothesis that timing of menarche may be set early in life but modified by changes in body size and composition in childhood. To evaluate this, a cohort of 255 girls aged $<5$ years recruited in 1988 were followed up in 2001 in Matlab, Bangladesh. The analysis was based on nutritional status as assessed by anthropometry and recalled age at menarche. Data were examined using lifetable techniques and the Cox regression model. The association between nutritional status indicators and age at menarche was examined in a multivariate model adjusting for potential confounding variables. Censored cases were accounted for. The median age at menarche was $15 \cdot 1$ years. After controlling for early-life predictors (birth size, childhood underweight, childhood stunting) it appeared that adolescent stunting stood out as the most important determinant of age at menarche. Adolescent stunting still resonates from the effect of stunting in early childhood (OR respectively $2.63(p<0 \cdot 01 \mathrm{CI}: 1 \cdot 32-5 \cdot 24)$ and $8 \cdot 47(p<0 \cdot 001$ CI: 3.79-18.93) for moderately and severely stunted under-fives as compared with the reference category). Birth size was not a significant predictor of age at menarche. It is concluded that age at menarche is strongly influenced by nutritional status in adolescence, notably the level of stunting, which is in turn highly dependent on the level of stunting in early childhood. A 'late' menarche due to stunting may be detrimental for reproductive health in case of early childbearing because of the association between height and pelvic size.
\end{abstract}

\section{Introduction}

The first important experience in a woman's reproductive career is the menarche, the first menstruation. A late menarche may run in the family. There is some evidence of 
genetic predisposition on timing of menarche, which is among others grounded on the finding that age at menarche of mothers and their daughters is positively correlated (Gray, 1993). However, the predictive power of age at menarche of a girl's mother is small (Graber et al., 1995). Genetic factors probably account for approximately 10\% to $15 \%$ of the observed variation in age at menarche (Gray, 1993).

It is widely recognized that nutritional status is one of the most important non-genetic determinants of menarche (Riley et al., 1993). In general, better nourished girls reach menarche earlier than undernourished girls (WHO, 2003). A review of studies on the determinants of menarche reflects a development that runs parallel to the shift from the 'life style paradigm' (with its emphasis on behavioural factors) to the 'early-life experience paradigm' (that studies critical periods during which there is elevated sensitivity to the environment and that is localized in time), and hence, the adoption of the life course approach in, for instance, epidemiology, the field of women's health and demography (Robinson, 1992; Kuh \& Ben-Shlomo, 1997; Kuh \& Hardy, 2002; Kuh et al., 2003; Ben-Shlomo \& Kuh, 2002). In the early 1970s, timing of menarche was believed to be 'triggered' by a certain critical weight (Frisch \& Revelle, 1969, 1971) but the evidence for this relationship was weak (Trussell, 1980). In later studies, other anthropometric indices such as adolescent height, mid-upper arm circumference and body mass index were (also) found to be positively associated with menarche (Delgado et al., 1985; Linhares et al., 1986; Maclure et al., 1991; Koprowski et al., 1999). More recently, there has been growing support for the possibility that timing of menarche may be set in utero or early in life but may be modified by changes in body size and composition in childhood (Silva dos Santos et al., 2003), a line of thinking which relates to the 'fetal origins of disease hypothesis' of Barker (Barker, 1992, 1998; Barker et al., 2001). However, as yet there are only a handful of reports that hint at fetal determinants of age at menarche (Rich-Edwards, 2002) and the mechanisms involved are still unclear (Cole, 2000).

Within the Bangladeshi population stunting seems to have become an embodied trait, and malnutrition in general has been prevalent for generations, as a result of which individuals are exposed to micro- and macro-nutritional deficiencies during both the prenatal and postnatal period. Particularly, women and children are malnourished (Ross et al., 1996; ICDDR,B, 2002; WHO, 2003). Bangladesh has the highest rate $(50 \%)$ of children born full-term with a weight at birth below $2500 \mathrm{~g}$ as a result of intrauterine growth retardation, which points to an intergenerational phenomenon (Pojda \& Kelley, 2002). Gestation and early childhood are sensitive or critical for the adolescent stage in life. A delay in early-life growth can hardly be stopped or reversed and after the age of two years the potential for catch-up growth is indeed limited when such children remain in poor environments (Gillespie \& Flores, 2000). In Bangladesh there is a well-documented list of factors (notably diarrhoea, other infectious diseases, adverse environmental conditions and unhealthy behaviours) that contribute to the 'chain of risks' or the pathway of cumulative causation (Kuh \& Ben-Shlomo, 1997) impacting nutritional anthropometry in the negative. However, if environmental conditions improve, particularly in terms of favourable nutrient intake, the period of adolescence could be a window of opportunity to catch up early-life growth faltering (WHO, 2003), although evidence of complete catch-up in developing countries is limited (Martorell et al., 1995; WHO, 2003). Studying the 
influence of nutritional status in early life, notably in early childhood, on age at menarche involves analyses of longitudinal data. To the authors' knowledge, there have been only a few such longitudinal studies conducted in developing countries (Kusin \& Kardjati, 1994; Martorell \& Scrimshaw, 1995; Ceesay et al., 1997; Moore et al., 2001; Stein et al., 2003). The main aim of this study was to examine whether age at menarche can be predicted on the basis of a nutritional status profile in adolescence and/or early life, i.e. in early childhood and at birth.

\section{Methods}

\section{Sample}

This study was conducted in three villages in the neighbourhood of the Matlab field station of the Centre for Health and Population Research (ICDDR,B), where the centre has maintained a Health and Demographic Surveillance System (HDSS) since 1966. Details of the study villages and selection criteria have been reported elsewhere (Bosch, 2005). The study involved the follow-up of 707 under-five children, among which 320 were girls, who were enrolled in an earlier study on childhood infectious diseases, conducted in Matlab in 1988-1989, by Baqui, a public health physician and epidemiologist affiliated with ICDDR,B (Baqui, 1990; Baqui et al., 1992, 1993a, 1993b). At the start of the baseline study, in April 1988, the youngest child enrolled was less than one month old, whereas the oldest child was almost five years old. The follow-up study took place in 2001. By that year the under-fives had grown up to be adolescents, aged 12 to 16 years. Linking of individual records was feasible because of the Registration Identification (RID) number in HDSS. A total of 255 adolescent girls were eligible for enrolment in the follow-up study. Analyses of lost cases due to migration and death has been described elsewhere (Bosch, 2005). At baseline, the cases lost for follow-up did not differ significantly from the other cases in terms of nutritional status and living circumstances. Informed written consent was obtained from the mother of each participating under-five child before enrolment in the baseline study, and from the adolescent girl as well as her mother or father in the follow-up study. At follow-up, data on age at menarche of the adolescent girl and her mother were collected by retrospective recall, in full years. Both at baseline and at follow-up, date of birth was provided by HDSS. Chronological age was assessed on the basis of date of birth and date of interview.

At baseline and at follow-up, anthropometric measurements were taken by trained research assistants and interviewers. At baseline, each under-five girl was weighed nude or with light clothes to the nearest $0.1 \mathrm{~kg}$ with a Salter-type spring scale. At follow-up, each adolescent girl was weighed wearing daily clothes to the nearest $0 \cdot 1$ $\mathrm{kg}$ with a digital weighing scale, following WHO guidelines (WHO, 1995). In both surveys, the scales were calibrated against known weights before use. Recumbent length of girls under 36 months and the standing height of girls $\geq 36$ months, as well as of adolescent girls and their mothers, were measured to the nearest $0 \cdot 1 \mathrm{~cm}$ using a locally constructed length board. In order to reduce observation errors, anthropometric measurements were read by two observers independently, both at baseline as well as at follow-up, and weight was measured twice. The mean of the two 
measurements was taken as the actual value. At baseline, $10 \%$ of the girls were measured the following day in order to assure the quality of the weight and height measurements. At follow-up, $10 \%$ of the girls and their mothers were measured again as well as re-interviewed about menarche.

Data on relative birth size were collected by means of retrospective recall from the adolescent's mother in 2001. The guidelines of Demographic and Health Surveys were followed. They indicate that in the absence of documentation on the baby's anthropometry at birth, a mother's verbal report of the baby's relative size, a report which relies on memory, is the only source available (DHS, 1997). Birth size was categorized as normal in size as compared with other babies, relatively small or relatively tall. In order to be on the safe side with assessing the prevalence of small-size babies among the study population, for analysis purposes a binary variable was created (small versus normal or tall).

\section{Data analysis}

Of the 255 girls available at enrolment 156 were pre-menarcheal, 97 were post-menarcheal, and for two girls menarche status was not known. Nearly $52 \%$ of the pre-menarcheal girls and over $93 \%$ of the post-menarcheal girls were 14 years or older at the time of interview. Maternal age at menarche was collected from 238 mothers. Nutritional status in early childhood and in adolescence was assessed for respectively 253 and 225 girls on the basis of international standards of anthropometric indices of $\mathrm{CDC} / \mathrm{WHO}$, i.e. weight-for-age or undernutrition, and height-for-age or stunting, and - only in adolescence - body mass index (BMI) indicating 'thinness' or chronic energy deficiency (CED) (WHO, 1995). Data on nutritional status were analysed by using the nutritional anthropometry program 'NutStat' from EPI info (CDC, 2000). Two different reference populations of the United States Centre for Health Statistics (US NCHS) were applied: the CDC/WHO reference population of 1978 to the nutritional analyses of the under-fives in 1988-1989 and the CDC reference population of 2000 to the nutritional analyses of the same population in adolescence in 2001. The rationale for this selection was that these two reference populations are as close as possible in time to the year of measurement of anthropometry of the study population in childhood and adolescence respectively. The under-five girls were measured a variable number of times, with a maximum of fourteen, within an approximate two-year period. In this study, early childhood nutritional status was determined by an average of up to fourteen consecutive anthropometric indices. The level of underweight in early childhood and the level of underweight in adolescence are expressed as an ordinal variable. Category 1 (not underweight) is $>-2 \mathrm{SD}$ from the median of the reference population; category 2 (moderately underweight) is between -3 and $-2 \mathrm{SD}$ from the median of the reference population; category 3 (severely underweight) is $<-3 \mathrm{SD}$ from the median of the reference population. The cut-off points for the three levels of childhood and adolescent stunting (i.e. not stunted, moderately stunted, severely stunted) are the same, as are the cut-off points for the three levels of adolescent CED, expressed by BMI $Z$-scores (i.e. not CED, moderately CED, severely CED). Of 249 girls the mother was able to report on the birth size: $28 \%$ reported that her daughter was small 
in size, $60 \%$ reported that her daughter was normal in size and $12 \%$ reported that her daughter was tall at birth.

Pearson's coefficient, a measure of linear association, was used for assessing the relationship between the dependent variable and independent variables, and Kendall's tau-b coefficient, a measure of association for nominal data, was used for assessing the extent of multi-collinearity between the independent variables. Binary logistic multivariate regression analyses (with 95\% CI) were applied to examine the impact of early-life predictors on adolescent stunting, the main contemporary nutritional status determinant of age at menarche.

Timing of menarche was studied by means of lifetable techniques. The effects of indicators of nutritional status were assessed using univariate and multivariate Cox regression models. The lifetable and the Cox model account for censored cases, i.e. girls who were still pre-menarcheal at the time of interview. The Cox model is a semi-parametric transition rate model, specified as follows:

$$
r(x)=h(x) \exp \left[a_{1} z_{1}+a_{2} z_{2}+\ldots a_{i} z_{i}\right],
$$

where $r(x)$ is the rate of menarche (transition rate, hazard rate) at age $x, h(x)$ is the baseline rate, $z_{i}$ is the $i^{\text {th }}$ predictor of the age at menarche (covariate) and $a_{i}$ is the impact of the predictor on the log rate of reaching menarche. In the current application, $z_{1}$ to $z_{i}$ relate to indicators of nutritional status in adolescence, early childhood or at birth, and maternal age at menarche. The baseline captures the effect of age and the second term captures the effects of covariates. The proportional hazards model assumes that the effects of covariates do not change with age. This assumption has been tested in the multivariate model. On the basis of Schoenfeld and scaled Schoenfeld residuals it was concluded that the assumption holds in the sample of observations, meaning that the hazards of the covariates do not change over time (with age). Variables that were significant at the $\leq 0.05$ level on the univariate model were included in the multivariate model. In the multivariate analysis, independent variables with high correlation (Kendall's tau-b coefficient $\geq 0 \cdot 6$ ) were not fitted simultaneously. For independent variables expressed as categorical, each category is compared with the reference category. Reference categories comprise girls who were not malnourished in adolescence and childhood according to anthropometry, or who were not small in size at birth. In the tables, only the main parameter of the model $(B)$ and the level of significance is shown, along with the corresponding standard error.

\section{Results}

The selected characteristics of the girls enrolled in the follow-up study are presented in Table 1. In the sample, many of the girls have not yet reached menarche: the proportion of post-menarcheal girls increases from 7\% among 12-year-old girls to $81 \%$ among 16-year-old girls. Over half $(52 \%)$ of the post-menarcheal girls reach menarche at an age of 14 years or older. The mean age at menarche of the girls' mothers is 14.4 years. Neither a significant correlation between a mother's age at menarche and menarche status (post-menarcheal or pre-menarcheal) of her adolescent 
Table 1. Characteristics of the study sample in Matlab, Bangladesh

\begin{tabular}{|c|c|c|c|}
\hline Variables & Categories & Mean \pm SD & $n$ \\
\hline Age (years) in adolescence & & $14 \cdot 0 \pm 1 \cdot 3$ & 255 \\
\hline \multirow{4}{*}{ Menarche status } & & & 255 \\
\hline & Post-menarcheal (\%) & 38 & \\
\hline & Pre-menarcheal $(\%)$ & 61 & \\
\hline & Unknown (\%) & $1^{\mathrm{a}}$ & \\
\hline \multirow{9}{*}{$\begin{array}{l}\text { Maternal age at menarche } \\
\text { Nutritional status in adolescence }\end{array}$} & & $14 \cdot 4 \pm 1 \cdot 6$ & 238 \\
\hline & & & 225 \\
\hline & Adolescent weight (kg) & $33 \cdot 1 \pm 6 \cdot 9$ & \\
\hline & Adolescent height $(\mathrm{cm})$ & $143 \cdot 1 \pm 8 \cdot 4$ & \\
\hline & Weight-for-age $Z$-score (WAZ) & $-3 \cdot 2 \pm 1 \cdot 7$ & \\
\hline & Height-for-age $Z$-score (HAZ) & $-2 \cdot 5 \pm 1 \cdot 1$ & \\
\hline & BMI-for-age $Z$-score (BMIZ) & $-1 \cdot 8 \pm 1 \cdot 2$ & \\
\hline & Underweight (WAZ<-3Z) $(\%)$ & 46 & \\
\hline & Stunted $(\mathrm{HAZ}<-3 Z)(\%)$ & 28 & \\
\hline \multirow{8}{*}{$\begin{array}{l}\text { Age (months) in early childhood } \\
\text { Nutritional status at first measurement } \\
\text { in early childhood }\end{array}$} & & $19 \cdot 5 \pm 13 \cdot 6$ & 255 \\
\hline & & & 253 \\
\hline & Under-five weight (kg) & $7 \cdot 5 \pm 2 \cdot 3$ & \\
\hline & Under-five height (cm) & $71 \cdot 9 \pm 10 \cdot 4$ & \\
\hline & Weight-for-age $Z$-score (WAZ) & $-2 \cdot 3 \pm 1 \cdot 6$ & \\
\hline & Height-for-age $Z$-score (HAZ) & $-2 \cdot 4 \pm 1 \cdot 3$ & \\
\hline & Underweight (WAZ<-3Z) $(\%)$ & 36 & \\
\hline & Stunted $(\mathrm{HAZ}<-3 Z)(\%)$ & 37 & \\
\hline \multirow[t]{3}{*}{ Birth size } & & & 24 \\
\hline & Small size at birth $(\%)$ & 28 & \\
\hline & Normal size or tall at birth $(\%)$ & 72 & \\
\hline
\end{tabular}

daughter (all girls included) was found, nor a significant correlation between a mother's age at menarche and the age at menarche of her post-menarcheal daughter. The majority of the girls are malnourished in both early childhood as well as adolescence in comparison with a well-nourished reference population of the same age and sex, and the proportion of girls with a small size at birth is equal to $28 \%$. The proportion of girls who were underweight as an under-five child is $36 \%$. In adolescence this proportion is $46 \%$. The corresponding figures for stunting are respectively $37 \%$ and $28 \%$. If the 16-year-old girls in the sample marry and become pregnant soon afterwards, respectively $83 \%$ and $23 \%$ will be at risk in terms of obstetric cut-off points for weight $(<45 \mathrm{~kg})$ and height $(<145 \mathrm{~cm})$.

Lifetable analyses reveal that the median age at menarche among the girls is $15 \cdot 1$ years. The survival function for adolescent girls showing the probability of being pre-menarcheal is presented in Fig. 1.

By means of Cox regression models (a) the stage in life (adolescence, early childhood or birth) that is most important with respect to the influence of nutritional status on menarche attainment; and (b) within this stage, the type of nutritional status indicator (underweight, stunting or BMI) that has the strongest effect are reviewed 


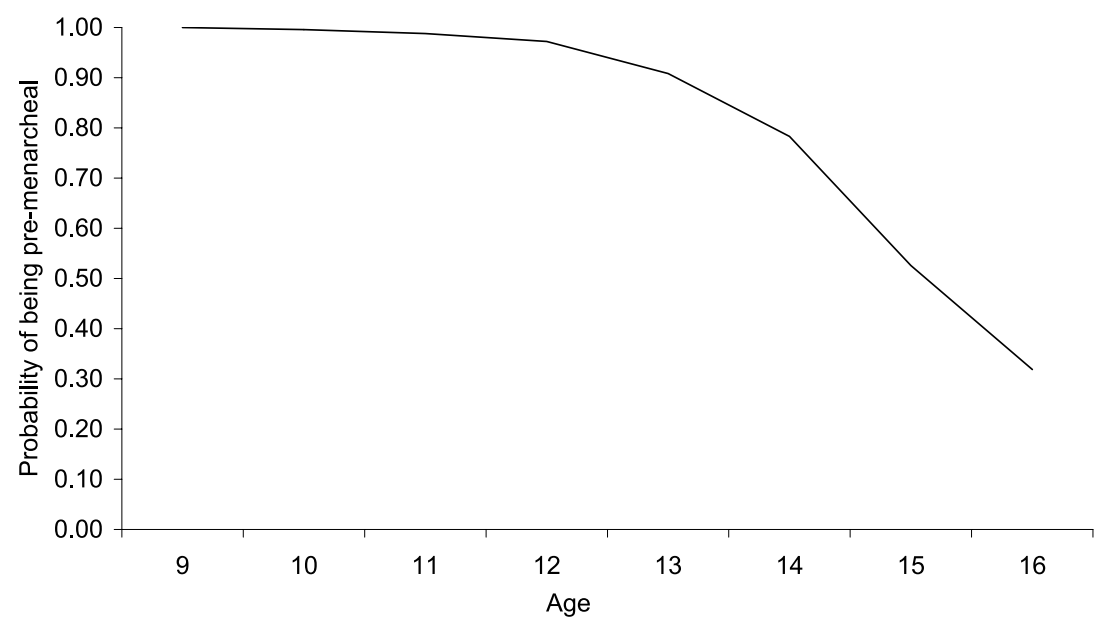

Fig. 1. Survival function for adolescent girls showing the probability of being pre-menarcheal by age (in years), Matlab 2001.

further. Table 2 shows the results of the univariate model, i.e. the model with a single covariate.

From Table 2 it can be observed that with regard to predicting the rate of menarche all indicators of nutritional status in adolescence are (highly) significant. Consider the effect of adolescent stunting on the rate of menarche: girls who are severely stunted in adolescence have a rate of menarche that is $16 \%$ $[\exp (-1.821) \times 100]$ of the rate for girls who are not stunted in adolescence (the reference group). Similarly, girls who are moderately stunted in adolescence have a rate of menarche that is $42 \%$ of the rate for girls who are not stunted in adolescence (the reference group). Given that a lower rate of menarche implies a higher age at menarche, these results reveal that girls who are severely stunted have the highest age at menarche. The effects of childhood underweight and childhood stunting are only significant if the severely malnourished categories are considered. Girls who were severely underweight and stunted in early childhood have a rate of menarche that is respectively $48 \%$ and $49 \%$ of the rate for girls who were not underweight and not stunted, respectively, in early childhood (the reference groups). Size at birth appears not to be a significant factor predicting the rate of menarche.

Also, Cox regression was applied to examine the effect of continuous independent variables (maternal age at menarche, adolescent weight and adolescent height). For instance, an increase in the age at menarche of the mother by one year will reduce the rate of menarche of the daughter by $7 \cdot 8 \%[(\exp (-0 \cdot 081)-1) \times 100]$, which in turn will imply a postponement of menarche of the daughter. However, maternal age at menarche does not appear to have a significant effect on the age of menarche, whereas adolescent weight and height do. An increase in adolescent weight and height of respectively one kilogram and one centimetre increases the rate of menarche by $11.6 \%$ and $11.2 \%$, respectively. Such an increase in rate of menarche relates to a more adequate nutritional status in terms of weight and height implying a decrease in age of menarche. 
Table 2. Cox regression univariate model predicting the rate of menarche, Matlab 1988-2001

\begin{tabular}{|c|c|c|c|}
\hline Variables & Categories, if applicable & $B$ & $\mathrm{SE}$ \\
\hline \multicolumn{2}{|c|}{ Maternal age menarche (continuous) } & -0.081 & 0.068 \\
\hline \multicolumn{2}{|c|}{ Adolescent weight (continuous) } & $0 \cdot 110 * * *$ & $0 \cdot 015$ \\
\hline \multicolumn{2}{|c|}{ Adolescent height (continuous) } & $0 \cdot 106 * * *$ & $0 \cdot 016$ \\
\hline \multirow{3}{*}{$\begin{array}{l}\text { Adolescent } \\
\text { underweight }\end{array}$} & Not underweight: $>-2$ SD (ref.) & - & - \\
\hline & Moderately underweight: between -3 and -2 SD & $-0 \cdot 518 *$ & $0 \cdot 242$ \\
\hline & Severely underweight $:<-3 \mathrm{SD}$ & $-1 \cdot 771 * * *$ & $0 \cdot 289$ \\
\hline \multirow{3}{*}{$\begin{array}{l}\text { Adolescent } \\
\text { stunting }\end{array}$} & Not stunted:> $-2 \mathrm{SD}$ (ref.) & - & - \\
\hline & Moderately stunted: between -3 and -2 SD & $-0 \cdot 857 * * *$ & $0 \cdot 233$ \\
\hline & Severely stunted: $<-3 \mathrm{SD}$ & $-1 \cdot 821 * * *$ & $0 \cdot 364$ \\
\hline \multirow{3}{*}{$\begin{array}{l}\text { Adolescent } \\
\text { CED according } \\
\text { to BMI } Z \text {-scores }\end{array}$} & Not CED: $>-2 \mathrm{SD}$ (ref.) & - & - \\
\hline & Moderately CED: between -3 and -2 SD & $-0.984 * *$ & $0 \cdot 312$ \\
\hline & Severely CED: $<-3$ SD & $-1 \cdot 804 * * *$ & $0 \cdot 517$ \\
\hline \multirow{3}{*}{$\begin{array}{l}\text { Childhood } \\
\text { underweight }\end{array}$} & Not underweight: $>-2 \mathrm{SD}$ (ref.) & - & - \\
\hline & Moderately underweight: between -3 and -2 SD & $-0 \cdot 044$ & $0 \cdot 251$ \\
\hline & Severely underweight: $<-3 \mathrm{SD}$ & $-0.734 * *$ & $0 \cdot 270$ \\
\hline \multirow{3}{*}{$\begin{array}{l}\text { Childhood } \\
\text { stunting }\end{array}$} & Not stunted:> $-2 \mathrm{SD}$ (ref.) & - & - \\
\hline & Moderately stunted: between -3 and -2 SD & $-0 \cdot 350$ & $0 \cdot 261$ \\
\hline & severely stunted: $<-3 \mathrm{SD}$ & $-0 \cdot 714 * *$ & $0 \cdot 259$ \\
\hline \multirow{2}{*}{$\begin{array}{l}\text { Recalled } \\
\text { birth size }\end{array}$} & Normal in size or tall (ref.) & & - \\
\hline & Small & $-0 \cdot 323$ & $0 \cdot 240$ \\
\hline
\end{tabular}

${ }^{*} p<0 \cdot 05 ; * * p<0 \cdot 01 ; * * * p<0 \cdot 001$.

This outcome raises the question of how the model with covariates (multivariate model) will look. More specifically, it was aimed to explore what the effect of a potential nutritional predictor is on the rate of menarche when controlling for other predictors included in the model. Four multivariate models are presented in Table 3. The most salient models, i.e. the models that show a significant change when an additional predictor is added, were selected.

In line with previous findings, adolescent stunting stands out as the most significant nutritional predictor for the rate of menarche (Models 1 to 4). Although adolescent underweight and BMI have a significant effect on the rate of menarche when considered on their own (see Table 2), they lose significance when they are considered together with adolescent stunting (Model 1). Moreover, childhood underweight (Model 2) and childhood stunting (Model 3) also do not affect the strong effect of adolescent stunting on the rate of menarche. When considered together with the respective early-life predictors of the rate of menarche in one model, the 
Table 3. Cox regression multivariate model predicting the rate of menarche, Matlab 1988-2001

\begin{tabular}{|c|c|c|c|c|c|}
\hline Variables & Categories & $\begin{array}{l}\text { Model } 1 \\
\qquad(B)\end{array}$ & $\begin{array}{l}\text { Model } 2 \\
\text { (B) }\end{array}$ & $\begin{array}{c}\text { Model } 3 \\
\text { (B) }\end{array}$ & $\begin{array}{l}\text { Model } \\
\text { (B) }\end{array}$ \\
\hline \multirow[t]{3}{*}{$\begin{array}{l}\text { Adolescent } \\
\text { underweight }\end{array}$} & $\begin{array}{l}\text { Not underweight: } \\
>-2 \text { SD (ref.) }\end{array}$ & - & - & - & - \\
\hline & $\begin{array}{l}\text { Moderately underweight: } \\
\text { between }-3 \text { and }-2 \text { SD }\end{array}$ & $-0 \cdot 265$ & -0.414 & -0.383 & $-0 \cdot 467$ \\
\hline & $\begin{array}{l}\text { Severely underweight: } \\
<-3 \text { SD }\end{array}$ & -0.808 & $-1 \cdot 107^{*}$ & $-1 \cdot 028^{*}$ & $-1 \cdot 173$ \\
\hline
\end{tabular}

Adolescent stunting

Childhood underweight

Childhood stunting

Adolescent
Not stunted:

$$
>-2 \text { SD (ref.) }
$$

Moderately stunted: between -3 and -2 SD

Severely stunted: $<-3$ SD CED according to BMI Z-scores

\section{Not CED:}

$>-2 \mathrm{SD}$ (ref.)

Moderately CED: between -3 and -2 SD

Severely CED: $<-3 \mathrm{SD}$

Not underweight:

$$
>-2 \text { SD (ref.) }
$$

Moderately underweight: between -3 and -2 SD

Severely underweight: $<-3$ SD

Not stunted:

$$
>-2 \mathrm{SD} \text { (ref.) }
$$

Moderately stunted: between -3 and -2 SD

Severely stunted: $<-3 \mathrm{SD}$

-2 log-likelihood Overall score $\chi^{2}$

df

Change from previous step $\left(\chi^{2}\right)$

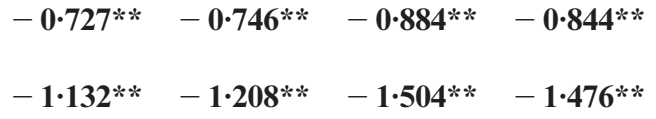

$0 \cdot 215$

$0 \cdot 511$

\begin{tabular}{|c|c|c|c|}
\hline $773 \cdot 854$ & $771 \cdot 796$ & $769 \cdot 149$ & $768 \cdot 421$ \\
\hline $58.985 * * *$ & $61 \cdot 116^{* * * *}$ & $61.678 * * *$ & $63 \cdot 460 * * *$ \\
\hline 6 & 8 & 8 & 10 \\
\hline $57 \cdot 570 * * *$ & $59 \cdot 175^{* * *}$ & $61.822 * * *$ & $62 \cdot 550 * * *$ \\
\hline
\end{tabular}

$0 \cdot 337$

${ }^{*} p<0 \cdot 05 ; *^{*} p<0 \cdot 01 ; * * * p<0 \cdot 001$. 
Table 4. Binary logistic univariate regression models: odds ratios (with 95\% CI) of adolescent stunting, Matlab 1988-2001

Variables $\quad$ Odds ratio Constant Nagelkerke $R^{2}$

Childhood underweight

Not underweight:

$>-2 \mathrm{SD}$ (ref.)

$1 \cdot 00$

$1 \cdot 029$

$0 \cdot 126$

Moderately underweight:

-3 to $-2 \mathrm{SD}$

$1 \cdot 94(0 \cdot 99-3 \cdot 81)$

Severely underweight:

$<-3 \mathrm{SD}$

$5 \cdot 51 * * *(2 \cdot 54-11 \cdot 94)$

Childhood stunting

Not stunted:

$>-2$ SD (ref.)

$1 \cdot 00$

$0 \cdot 850$

$0 \cdot 191$

Moderately stunted:

-3 to -2 SD

$2 \cdot 63^{* *}(1 \cdot 32-5 \cdot 24)$

Severely stunted:

$<-3 \mathrm{SD}$

$8 \cdot 47 * * *(3 \cdot 79-18 \cdot 93)$

${ }^{*} p<0 \cdot 05 ; * * p<0 \cdot 01 ; * * * p<0 \cdot 001$.

significant effect of adolescent stunting on the rate of menarche hardly changes (Model 4). Taking Model 4 as an example, it can be found that - when controlling for nutritional status in early life - girls who are moderately stunted in adolescence have a rate of menarche that is $43 \%[\exp (-0.844) \times 100]$ of the rate for girls who are not stunted in adolescence (the reference group). Similarly, girls who are severely stunted in adolescence have a rate of menarche that is $23 \%$ of the rate for girls who are not stunted in adolescence (the reference group).

The robust effect of adolescent stunting on the rate of menarche while considering the respective early-life predictors is a result of multi-colliniarity. Adolescent stunting is strongly related to stunting during childhood. Using logistic regression a highly significant effect is found on the odds of being stunted (i.e. not stunted versus moderately or severely stunted) in adolescence for girls who were moderately and severely stunted in childhood as compared with girls who had a normal height according to their age and sex in childhood (i.e. the not stunted under-fives) (see Table 4).

For instance, it can be observed that the odds of being stunted in adolescence for girls who were moderately stunted in childhood are 2.63 times $(p<0 \cdot 01 \mathrm{CI}: 1 \cdot 32-5 \cdot 24)$ the odds for girls who were not stunted in childhood (reference category), whereas the odds of being stunted in adolescence for girls who were severely stunted in childhood are even higher (8.47 times higher; $p<0.001$ CI: 3.79-18.93).

\section{Discussion}

Results of this study provide strong evidence that in the study area menarche is reached 'late' as compared with contemporary Western countries (Becker, 1993). The 
age of 14 is selected as the cut-off point to distinguish early/on time and late menarche. Adolescent girls who were malnourished according to anthropometry as an under-five child are more likely to reach menarche at an age of 14 years or older as compared with their well-nourished under-five counterparts. The strongest predictor of a 'late' age at menarche appears to be a low contemporary nutritional status, particularly indicated by severe stunting. However, the multivariate analysis indicates that it cannot be concluded that only adolescent stunting impacts on menarche attainment and that adolescent weight (or weight-for-age) and nutritional status in childhood are not factors of importance. Given that in extreme situations (famine, diet, physical exercise) menstruation (temporarily) stops there seems to be a minimum of nutritional intake required for normal reproductive functioning. Such a minimum, or 'critical weight' (Frisch \& Revelle, 1971), is also likely to be present for the first menstruation, menarche. Given the strong correlation that was found between stunting in early childhood and adolescence, adolescent stunting still resonates from the effect of stunting in early childhood. Following the same line of thinking, the effects of nutritional status of the previous generation (the adolescent girls' mothers) should also not be ruled out as a factor possibly (indirectly) influencing age at menarche. For instance, maternal height did not have a significant effect on the rate of menarche, but it appeared to be a significant determinant of adolescent stunting (OR 4.19, $p<0 \cdot 01$ CI: 1.56-11.27). Path analysis could shed light on the relative impact of each of these variables on the age at menarche.

A limitation of the study is that the data on menarche were collected by retrospective recall. The recall method of reporting age at menarche may not be optimal, but is usually the only source of available information (Graham et al., 1999) and accuracy of short-term recall among adolescent girls can be relatively high (Koo \& Rohan, 1997). Also, some - relatively old - studies (Becker, 1993) point out that recall errors are fairly random, i.e. show no systematic bias in retrospective reports. The quality of the data on age at menarche of the girls' mothers is even more likely to suffer from the long period of recall. Maternal age at menarche was, however, not significantly related to the age at menarche of the daughter - possibly due to random recall errors which might have reduced the degree of association - and consequently excluded from the multivariate model.

Age at menarche is not entirely beyond control, given that it is, at least in part, determined by behavioural (i.e. nutritional) factors. A girl who finds herself on the threshold of adolescence may indeed not be able anymore to alter the timing of her coming menarche. However, for malnourished girls in early childhood (particularly in infancy), but possibly also in late childhood, i.e. between the ages of 6 and 12 years (a population under-addressed in contemporary research), it may still be feasible to improve nutritional status. On the basis of stunting profiles in particular, monitoring systems should be formulated, aiming at singling out those pre-adolescent girls who run a risk of reaching their menarche 'late' so as to programme urgent nutritional aid for them. Maintenance of proper nutritional status from birth onwards also adds to mental well-being in later life (Lachance, 1995; Gillespie \& Flores, 2000).

The significance of this study relates also to future transitions embedded within the reproductive career, notably the first pregnancy and childbirth. A positive connotation of 'late' menarche is that it could be seen as some kind of 'natural 
protection' for early reproduction in severely malnourished populations such as the one described here. However, this argument may lose relevancy in view of the gradual increase in age at marriage in Bangladesh, which seems associated with increasing levels of female education rather than girls' physical development process. Menarche no longer indicates 'readiness for marriage', as used to be the case in this country (Riley et al., 1993).

However, despite of the increasing trends, the mean age at marriage and age at first birth in Bangladesh remain relatively low. For instance, $63 \%$ of the girls in this country have given birth by the age of 20 years (Population Reference Bureau, 2000). Viewed from this perspective, reaching menarche at the age of 14 years or older seems to be detrimental for reproductive health if such a relatively 'late' menarche is followed shortly by the birth of the first child and the girl's height is low. This notion is grounded in the recognition that (a) height and pelvic size are correlated; and (b) at the time of reaching menarche girls have approximately $4 \%$ more height and $12-18 \%$ more pelvic growth ahead of them (WHO, 1991). Consequently, these girls would typically reach physical 'readiness' for childbirth also at a later stage. It is as yet not known exactly how a pregnancy in an adolescent girl interferes with her own growth and reproductive maturation process (Riley et al., 1993). There are indications that catch-up early-life growth faltering in adolescent girls is characterized by a growth that continues longer than usual, while growth velocity does not change (Riley, 1994; Silventoinen, 2000).

The adolescent girls in the sample were likely not to have completed growth but their height and weight seem also to be sub-normal because of malnutrition. In absolute terms, some of the girls in this study were at risk because their weight and height fall below the cut-off points below which obstetric risks increase (WHO, 2003). Specifically, if the 16-year-old girls in the sample married and became pregnant soon afterwards, $83 \%$ and $23 \%$ respectively would be at risk in terms of obstetric cut-off points for weight and height.

In sum, crucial for an adolescent girl's reproductive health status seems spacing between menarche and first birth. Such a significance of spacing argues in favour of a focus in policy and IEC activities on gynaecological age, i.e. the time in years since menarche (Becker, 1993) and biological age (indexed by nutritional status) rather than chronological age.

\section{Acknowledgments}

This research was supported by the Netherlands Foundation for the Advancement of Tropical Research (WOTRO) and its completion was achieved through financial support from the Netherlands Interdisciplinary Demographic Institute (NIDI) and the Population Research Centre (PRC) of Groningen University, for which the authors are most grateful. The authors sincerely acknowledge the contribution of the staff of the Centre for Health and Population Research (ICDDR,B) in Dhaka and Matlab. In particular, they are indebted to Mr Chakraborty, Mrs Khaleda Khanam, Dr Kim Streatfield and Dr Abbas Bhuiya. They also thank Dr Sjoerd Elias of the University Medical Center Utrecht for his valuable comments. 


\section{References}

Baqui, A. H. (1990) Epidemiology of persistent diarrhoea in Bangladeshi children. PhD thesis, Johns Hopkins University, Baltimore.

Baqui, A. H., Black, R. E., Sack, R. B., Chowdhury, H. R., Yunus, M. \& Siddique, A. K. (1993a) Malnutrition, cell-mediated immune deficiency, and diarrhoea: a community-based longitudinal study in rural Bangladeshi children. American Journal of Epidemiology 137(3), 355-365.

Baqui, A. H., Black, R. E., Sack, R. B., Yunus, M. D., Siddique, A. K. \& Chowdhury, H. R. (1992) Epidemiological and clinical characteristics of acute and persistent diarrhoea in rural Bangladeshi children. Acta Paediatrica (supplement) 381, 1-7.

Baqui, A. H., Sack, R. B., Black, R. E., Chowdhury, H. R., Yunus, M. \& Siddeque, A. K. (1993b) Cell-mediated immune deficiency and malnutrition are independent risk factors for persistent diarrhoea in Bangladeshi children. American Journal of Clinical Nutrition 58, $543-548$.

Barker, D. J. P. (ed.) (1992) Fetal and Infant Origins of Adult Disease. Papers written by The Medical Research Council Environmental Unit, University of Southampton; British Medical Journal.

Barker, D. J. P. (1998) Mothers, Babies and Disease in Later Life. British Medical Journal Publishing Group, London.

Barker, D. J. P., Forsén, T., Uutela, A., Osmond, C. \& Eriksson, J. G. (2001) Size at birth and resilience to effects of poor living conditions in adult life: longitudinal studies. British Medical Journal 323(7324), 1273.

Becker, S. (1993) The determinants of adolescent fertility with special reference to biological variables. In Gray, R., Leridon, H. \& Spira, A. (eds) Biomedical Determinants of Reproduction. Clarendon Press, Oxford, pp. 21-49.

Ben-Shlomo, Y. \& Kuh, D. (2002) A life course approach to chronic disease epidemiology: conceptual models, empirical challenges and interdisciplinary perspectives. International Journal of Epidemiology 31, 283-293.

Bosch, A. (2005) Adolescents' reproductive health in rural Bangladesh: the impact of early childhood nutritional anthropometry. PhD thesis, University of Groningen, Groningen. Dutch University Press, Amsterdam.

Ceesay, S. M., Prentice, A. M., Cole, T. J., Foord, F., Weaver, L. T., Poskitt, E. M. E. et al. (1997) Effects on birth weight and perinatal mortality of maternal dietary supplements in rural Gambia: 5 years randomised controlled trial. British Medical Journal 315, 786-790.

Centers for Disease Control and Prevention (CDC) (2000) Epi Info 2000. NutStat, a Nutritional Anthropometry Program (Version 1-1.2). CDC, Atlanta, Georgia, pp. 79-91.

Cole, T. J. (2000) Secular trends in growth. Proceedings of the Nutrition Society 59, 317-324.

Delgado, H. L., Hurtado, E. \& Valverde, V. (1985) Physical growth, age at menarche and age at first union in rural Guatemala. Ecology of Food and Nutrition 16, 127-133.

Demographic and Health Surveys (DHS) (1997) Interviewer's Manual. DHS-III Basic Documentation-3. Macro International Inc., Calverton, MD.

Frisch, R. E. \& Revelle, R. (1969) Variation in body weights and the age of the adolescent growth spurt among Latin American and Asian populations, in relation to calorie supplies. Human Biology 41, 185-212.

Frisch, R. E. \& Revelle, R. (1971) The height and weight of girls and boys at the time of initiation of the adolescent growth spurt in height and weight and the relation to menarche. Human Biology 43, 140-159.

Gillespie, S. \& Flores, R. (2000) 1999-2000 Annual Report. Eradicating Malnutrition. Document posted on http://www.ifpri.cgiar.org/pub/books. 
Graber, J. A., Brooks-Gunn, J. \& Warren, M. P. (1995) The antecedents of menarche age: heredity, family environment, and stressful life events. Child Development 66, 346-359.

Graham, M. J., Larsen, U. \& Xiping, X. (1999) Secular trend in age at menarche in China: a case study of two rural counties in Anhui province. Journal of Biosocial Science 31(2), 257-267.

Gray, R. (1993) Biological factors other than nutrition and lactation which may influence natural fertility: a review. In Gray, R., Leridon, H. \& Spira, A. (eds) Biomedical Determinants of Reproduction. Clarendon Press, Oxford, pp. 219-250.

ICDDR,B (2002) Annual Report 2001. Centre for Health and Population Research, Dhaka.

Koo, M. M. \& Rohan, R. E. (1997) Accuracy of short-term recall of age at menarche. Annals of Human Biology 24(1), 61-64.

Koprowski, C., Ross, R. K., Mack, W. J., Henderson, B. E. \& Bernstein, L. (1999) Diet, body size and menarche in a multiethnic cohort. British Journal of Cancer 79, 1907-1911.

Kuh, D. \& Ben-Shlomo, Y. (eds) (1997) A Life Course Approach to Chronic Disease Epidemiology. Oxford University Press, Oxford.

Kuh, D., Ben-Shlomo, Y., Lynch, L., Hallqvist, J. \& Power, C. (2003) Life course epidemiology: glossary. Journal of Epidemiology and Community Health 57, 778-783.

Kuh, D. \& Hardy, R. (eds) (2002) A Life Course Approach to Women's Health. Oxford University Press, Oxford.

Kusin, J. A. \& Sri Kardjati (eds) (1994) Maternal and Child Nutrition in Madura, Indonesia. Royal Tropical Institute (KIT), Amsterdam.

Lachance, P. A. (1995) Recommended dietary allowance for growth, development and performance. Asia-Pacific Journal of Clinical Nutrition 4 (supplement 1), 7-12.

Linhares, E. D. R., Round, J. J. \& Jones, D. A. (1986) Growth, bone maturation and biochemical changes in Brazilian children from two different socioeconomic groups. American Journal Clinical Nutrition 44, 552-558.

Maclure, M., Travis L. B., Willet, W. \& MacMahon, B. (1991) A prospective cohort study on nutrient intake and age at menarche. American Journal of Clinical Nutrition 54, 649-656.

Martorell, R., Schroeder, D. G, Rivera, J. \& Kaplopwitz, H. J. (1995) Patterns of linear growth in rural Guatemalan adolescents and children. Supplement: the INCAP Follow-up study. Journal of Nutrition 25 (supplement 4s), 1060-1067.

Martorell, R. \& Scrimshaw, N. S. (eds) (1995) The effects of improved nutrition in early childhood: the Institute of Nutrition of Central America and Panama (INCAP) follow-up study. Journal of Nutrition 25 (supplement 4s) 1027-1138.

Moore, S. E., Collinson, A. C. \& Prentice, A. M. (2001) Immune function in rural Gambian children is not related to season of birth, birth size, or maternal supplementation status. American Journal of Clinical Nutrition 74(6), 840-847.

Pojda, J. \& Kelley, L. (2000) Low Birthweight. A report based on the International low birthweight symposium and workshop held on 14-17 June 1999 at the ICDDR,B. ACC/SCN Nutrition Policy Paper 18. World Health Organization, Geneva.

Population Reference Bureau (2000) The World's Youth 2000: Data Sheet. Measure Communication, Washington DC.

Rich-Edwards, J. (2002) A lifecourse approach to women's reproductive health. In Kuh, D. \& Hardy, R. (eds) A Life Course Approach to Women's Health. Oxford University Press, Oxford, pp. 23-43.

Riley, A. P. (1994) Determinants of adolescent fertility and its consequences for maternal health, with special reference to rural Bangladesh. Annals of the New York Academy of Sciences 18(709), 86-100. 
Riley, A. P., Samuelson, J. L. \& Huffman, S. L. (1993) The relationship of age at menarche and fertility in undernourished adolescents. In Gray, R., Leridon, H. \& Spira, A. (eds) Biomedical Determinants of Reproduction. Clarendon Press, Oxford, pp. 50-61.

Robinson, J. R. (1992) Introduction. In Barker, D. J. P. (ed) Fetal and Infant Origins of Adult Disease. University of Southampton. British Medical Journal, pp. 1-20.

Ross, J. L., Chowdhury, S. N. M. \& Mirza, T. (1996) Health, Gender, Sexuality. Bangladesh country report. Centre for Health and Population Research, Dhaka.

Silva dos Santos, I., Stavola, de B.L., Mann, V., Kuh, D., Hardy, R. \& Wadsworth, W. E. J. (2003) Prenatal factors, childhood growth trajectories and age at menarche. International Journal of Epidemiology 31, 405-412.

Silventoinen, K. (2000) Body-height: determinants and associations with social position and adult health. PhD thesis, University of Helsinki, Helsinki.

Stein, A. D., Barnhart, H. X., Hickey, M., Ramakrishnan, U., Schroeder, D. G. \& Martorell, R. (2003) Prospective study of protein-energy supplementation early in life and of growth of subsequent generation in Guatemala. American Journal of Clinical Nutrition 78, 162-167.

Trussell, J. (1980) Statistical flaws in evidence for the Frisch hypothesis that fatness triggers menarche. Human Biology 52(4), 711-720.

WHO (1991) Maternal Mortality: A Global Factbook. World Health Organization, Geneva.

WHO (1995) Adolescents. Physical Status: The Use and Interpretation of Anthropometry. Report of a WHO expert Committee. WHO Technical Report Series 854. World Health Organization, Geneva, pp. 263-311.

WHO (2003) Adolescent Nutrition in South-East Asia: A Review of the Current Situation. Draft. World Health Organization, Geneva; Regional Office of South-East Asia, New Delhi. 